EXTENDED REPORT

\title{
Threshold retinopathy at threshold of viability: the EpiBel study
}

\author{
K Allegaert, K de Coen, H Devlieger, on behalf of the EpiBel Study group
}

Br J Ophthalmol 2004;88:239-242. doi: 10.1136/bjo.2003.027474

See end of article for authors' affiliations

.....................

Correspondence to: $\mathrm{K}$ Allegaert, MD,

University Hospitals, Gasthuisberg, Herestraat 49, 3000 Leuven, Belgium; karel.allegaert@ uz.kuleuven.ac.be

Accepted for publication 1 August 2003
Aim: To describe incidence, co-morbidity characteristics, and risk factors associated with threshold retinopathy of prematurity (ROP) in survivors with a gestational age (GA) of $\leqslant 26$ weeks at birth.

Methods: Retrospective analysis of perinatal data of all inborn survivors in all perinatal centres of Belgium in the period 1999-2000 (EpiBel cohort) believed to be between 22 and 26 weeks GA at time of delivery. Data on survivors who did and survivors who did not develop threshold ROP were compared ( $\chi^{2}$, MannWhitney U) and logistic regression was performed.

Results: Of 303 admitted infants 175 (58\%) were discharged alive. Incidence of major retinopathy ( $\geqslant$ stage 3 ) and of threshold ROP was $25.5 \%$ and $19.8 \%$ in survivors. Associated central nervous abnormalities were documented in six (17\%) and associated chronic lung disease in 19 (54\%) threshold ROP infants. Threshold ROP without additional morbidity characteristics at discharge was documented in $14(40 \%)$ infants. Besides often reported risk factors, renal insufficiency (creatinaemia $>1.5 \mathrm{mg} / \mathrm{dl}$ ) was a risk factor to develop threshold ROP $(p<0.0015)\left(\chi^{2}\right)$. Days of respiratory support (OR $1.02 ; 95 \% \mathrm{Cl}$ 1.002 to 1.039 ), number of transfusions (OR 1.118; $95 \% \mathrm{Cl} 1.030$ to 1.214 ), and renal insufficiency (OR $3.31 ; 95 \% \mathrm{Cl} 1.344$ to 8.196 ) remained independent risk factors to develop threshold ROP in this cohort in a stepwise logistic regression model (MedCalc).

Conclusions: Incidence of threshold ROP is high at the limits of viability. Renal insufficiency is a risk factor to develop threshold ROP in this cohort.
$\mathrm{R}$ etinopathy of prematurity (ROP) is an important outcome variable of morbidity at discharge, especially in infants at threshold of viability. This complication of preterm birth is still a relevant cause of visual impairment in later life and is often associated with other developmental or motor disabilities. ${ }^{1}$

Until strategies are available to prevent preterm birth itself, caregivers have to focus on perinatal risk factors involved in an attempt to develop secondary preventive strategies or to unravel pathogenic processes involved.

In the EpiBel study, all infants born in the period 19992000 in the 19 perinatal centres of Belgium were included if they had a gestational age (GA) of 22 to 26 weeks and were alive at initiation of labour. ${ }^{2}$ In this paper, we focus on incidence, associated co-morbidity at discharge and perinatal risk factors of threshold ROP in survivors of this cohort.

\section{PATIENTS AND METHODS}

The EpiBel study retrospectively collected data in all 19 perinatal centres in Belgium between 1 January 1999 and 31 December 2000. All inborn births believed to be between 22 and 26 completed weeks of gestation at time of delivery and with signs of life noted at onset of labour were included. Data on 525 infants were collected. Of these infants, 303 were admitted in a neonatal intensive care unit and 175 survived until discharge. The overall survival rate in liveborn infants increased from $6 \%$ at 23 weeks to $71 \%$ at 26 weeks GA. During the same period, 58 infants ( $G A \leqslant 26$ weeks) were admitted in these units after being born outside one of the perinatal centres. These infants were left out of the EpiBel study since inclusion might introduce an additional bias if more stable infants were referred while unstable infants more probably might die before referral was considered. Only data in survivors - that is, alive at discharge, were analysed in this paper. A more comprehensive description of all infants, items collected, and methodology used in the EpiBel study is available. $^{2}$

Retinopathy of prematurity was classified according to the International Classification of Retinopathy of Prematurity. ${ }^{3}$ GA was calculated using the expected date of delivery based on an ultrasound performed before 20 weeks gestation, or if not available, on neonatal clinical findings. Maternal data collected and analysed in this cohort were way of conception, being either spontaneous or any assisted procedure (insemination, hormonal induction, in vitro fertilisation), hypertensive maternal complications during pregnancy (either isolated hypertension or pre-eclampsia), tocolysis administered (betamimetics, indomethacin), rupture of membranes $>24$ hours before delivery, documented amnionitis, mode of delivery, and being part of a multiple pregnancy. Collected data at birth were sex (boy/girl) and birth weight. Apgar score at 5 minutes was registered and CRIB score was calculated. ${ }^{4}$ Growth restriction at birth (10th percentile) in this population was documented based on charts of birth weight by GA in a population of preterm infants in the same geographic area. ${ }^{5}$ During neonatal stay data on gastroenteric, respiratory, cardiovascular, neurological, surgical and metabolic conditions were collected and analysed. Gastroenteric: gastrointestinal perforation (Bell's stage $\geqslant 3$ ), cholestasis any time during neonatal stay (direct bilirubin above $2 \mathrm{mg} / \mathrm{dl}$ ), exclusive breastfeeding and length (days) of parenteral nutrition. Respiratory characteristics were administration of surfactant, length of endotracheal ventilation (days), length of respiratory support (days), and length of supplemental oxygen administered (days). Chronic lung disease (CLD) at day 28 and at 36 GA was documented and any use of postnatal systemic steroid therapy was registered. Cardiovascular characteristics analysed were medical or surgical treatment of patent ductus arteriosus (PDA) and the use of inotropics during neonatal stay. Neurological characteristics recorded were intraventricular 
haemorrhage (IVH) (>grade 1) and leucomalacia, documented by the worst ultrasound available. IVH was classified by Papile criteria. Metabolic characteristics collected were the incidence of renal insufficiency, transient (any time), prolonged (after day 3 and for more than 5 days) or permanent (at discharge). Renal insufficiency was defined as a documented creatinaemia above $1.5 \mathrm{mg} / \mathrm{dl}$ or $135 \mu \mathrm{mol} / \mathrm{l}$. At least one session of phototherapy during neonatal stay was used as indicator of indirect hyperbilirubinaemia. The number of blood transfusions was documented and administration of erythropoietin (EPO) was registered.

All infants were examined on a regular basis by an experienced (paediatric) ophthalmologist. Examination were performed after dilatation using indirect ophthalmoscopy.

Infants who developed threshold retinopathy were cases and all other survivors were controls.

Results were reported by mean (SD) or by incidence. Incidence of major ( $\geqslant$ stage 3 ) and threshold ROP was calculated in survivors at discharge.

Data were studied using $\chi^{2}$ analysis, Mann-Whitney $\mathrm{U}$, or $t$ test. Finally, multiple and logistic regression (MedCalc, Medisoftware, Mariakerke, Belgium) were used to study independency of variables if significant in monovariate analysis. A p value of $<0.05$ was considered significant.

\section{RESULTS}

\section{Incidence (table 1)}

In 175 survivors, 45 (25.5\%) developed major ( $\geqslant$ stage 3 ) ROP and 35 (19.8\%) developed threshold ROP. Cryotherapy was used in 28 and laser therapy in seven infants.

\section{Co-morbidity characteristics (documented from birth until discharge) (table 1)}

Overall incidence of threshold ROP was $19.8 \%$. Nineteen $(10.6 \%)$ infants combined threshold retinopathy with CLD at 36 weeks GA and six (3\%) infants had CNS abnormalities (ventriculomegaly and/or parenchymal cysts) at discharge. Two infants combined CNS abnormalities and CLD with threshold ROP. Threshold ROP was the "only" marker of morbidity at discharge ("isolated") in $14(8 \%)$ infants.

\section{Risk factors (table 2)}

In a monovariate analysis, no maternal risk factors to develop threshold ROP were documented. GA, birth weight, Apgar score at 5 minutes, and CRIB score were risk factors to develop threshold ROP. In addition, duration of parenteral nutrition, ventilatory or respiratory support, duration of oxygen administration and CLD at 28 days and 36 weeks, the use of systemic steroids, incidence of renal insufficiency, and the number of blood transfusions were risk factors significantly associated with the risk to develop threshold ROP.

Renal insufficiency was documented in $46 \%$ of threshold cases and in $15 \%$ of controls. Neonatal characteristics in infants who developed renal insufficiency compared to infants who did not developed renal insufficiency are shown in table 3. Birth weight and GA were significantly lower in cases while CRIB score and the number of transfusions were significantly higher in cases. Renal insufficiency remained an independent risk factor $(\mathrm{p}<0.01)$ for the development of threshold ROP in a multiple regression model with maternal hypertension, growth restriction, treatment of PDA, and amnionitis as additional co-variables. These indicators were studied because of their potentially renal side effects in the neonate.

Finally, in a stepwise logistic regression model, duration of respiratory support (OR 1.020), number of blood transfusions (OR 1.118), and renal insufficiency (OR 3.319) were independent risk factors to develop threshold retinopathy (table 4).

\section{DISCUSSION}

The incidence of major retinopathy ( $\geqslant$ grade 3 ) in the EpiBel cohort was $25.5 \%$. Threshold retinopathy was $19.8 \%$. This incidence is in line with other European cohorts but is high when compared to American cohorts (table 1). ${ }^{6-10}$ This might at least partially be explained by the high incidence of white infants in European cohorts.

Threshold retinopathy was an isolated morbidity at discharge in $14(7,9 \%)$ survivors of the EpiBel cohort. Threshold ROP in combination with CLD at 36 weeks GA was documented in $10.6 \%$ of survivors and 3\% combined threshold ROP with CNS abnormalities ad discharge in the EpiBel cohort. These co-morbidity characteristics are in line with other reports in the literature (table 1).6 8

Although there are reports on maternal risk factors associated with threshold ROP, we could not find any significant risk factor in this cohort. ${ }^{11}{ }^{12}$. De Jonge could not document a protective effect on the development of major retinopathy in an analogous ( $\leqslant 26$ weeks GA) population, while Higgins documented a protective effect of prenatal steroids on ROP ( $\geqslant$ stage 2 ) in a cohort of premature infants with a birth weight below 1250 g. ${ }^{8}{ }^{13}$ Unfortunately, we do not have data on the use of prenatal steroids in the EpiBel cohort.

Even in this very immature population, GA still remained a risk factor to develop threshold ROP. In contrast with cohorts described by Bardin, Wallace, and a recent Belgian single centre case-control study, growth restriction at birth was not associated with an increased risk to develop threshold ROP in this cohort. ${ }^{10} 14{ }^{15}$ This, most likely, can be explained by the overall high incidence of threshold ROP in immature ( $\leqslant 26$ weeks GA) infants, while growth restriction might be more relevant in relatively more mature (27-29 weeks GA) infants in whom incidence of threshold retinopathy is much lower making the impact of additional risk factors easier to recognise. Lower Apgar score at 5 minutes and higher CRIB score were associated with an increased risk to develop

Table 1 Incidence and co-morbidity in survivors of the EpiBel cohort compared to other cohorts described in literature. Survival rate was calculated based on the total number of admitted infants

\begin{tabular}{|c|c|c|c|c|c|c|}
\hline & EpiBel & EpiCure $^{6}$ & Larsson $^{7}$ & De Jonge ${ }^{8}$ & Hussain 9 & Bardin $^{10}$ \\
\hline Gestational age (weeks) & $\leqslant 26$ & $<26$ & $\leqslant 26$ & $\leqslant 26$ & $\leqslant 26$ & $\leqslant 26$ \\
\hline Survival rate & $58 \%$ & $39 \%$ & NA & $68 \%$ & NA & $62.5 \%$ \\
\hline Number of survivors & 175 & 314 & 57 & 157 & 243 & 115 \\
\hline Major ( $\geqslant$ stage 3 ) ROP & $25.5 \%$ & NA & $35 \%$ & $26.8 \%$ & $14.4 \%$ & $20.8 \%$ \\
\hline Threshold ROP & $19.8 \%$ & $14 \%$ & NA & NA & $3.7 \%$ & NA \\
\hline \multicolumn{7}{|l|}{ Associated morbidity } \\
\hline$C L D$ & $10.6 \%$ & $9.8 \%$ & NA & NA & NA & NA \\
\hline CNS at discharge & $3 \%$ & $6.2 \%$ & NA & $3.2 \%$ & NA & NA \\
\hline Isolated & $8 \%$ & $4.7 \%$ & NA & NA & NA & NA \\
\hline
\end{tabular}


Table 2 Perinatal risk factors studied for potential association with the development of threshold ROP. Results are reported by incidence (\%) or by mean and SD

\begin{tabular}{|c|c|c|c|}
\hline & Controls & Cases & $\mathrm{p}$ Value \\
\hline Number of infants & 140 & 35 & \\
\hline \multicolumn{4}{|l|}{ Maternal factors } \\
\hline Assisted conception & $13 \%$ & $29 \%$ & NS \\
\hline Maternal hypertension & $13 \%$ & $6 \%$ & NS \\
\hline Tocolysis betamimetics & $64 \%$ & $69 \%$ & NS \\
\hline Tocolysis indomethacin & $10 \%$ & $11 \%$ & NS \\
\hline $\mathrm{ROM}>24$ hours & $73 \%$ & $83 \%$ & NS \\
\hline Amnionitis & $47 \%$ & $34 \%$ & NS \\
\hline Caesarean & $45 \%$ & $48 \%$ & NS \\
\hline $\begin{array}{l}\text { Multiple birth } \\
\text { At birth }\end{array}$ & $30 \%$ & $43 \%$ & NS \\
\hline Sex (boy) & $52 \%$ & $54 \%$ & NS \\
\hline Gestational age & $25.5(0.7)$ & $25.2(0.7)$ & $<0.005$ \\
\hline Weight at birth (g) & $815(155)$ & $743(166)$ & $<0.05$ \\
\hline Growth restricted (<10th) & $15 \%$ & $28 \%$ & NS \\
\hline Apgar 5 minutes & $7.7(1.6)$ & $7.1(1.3)$ & $<0.05$ \\
\hline CRIB score & $5.3(3.3)$ & $6.7(2.9)$ & $<0.05$ \\
\hline \multicolumn{4}{|l|}{ During neonatal stay } \\
\hline Intestinal perforation & $7 \%$ & $6 \%$ & NS \\
\hline Cholestasis & $14 \%$ & $23 \%$ & NS \\
\hline Breast feeding & $35 \%$ & $9 \%$ & NS \\
\hline Parenteral nutrition (days) & $38.7(24.5)$ & $56.7(28.8)$ & $<0.005$ \\
\hline Surfactant administered & $74 \%$ & $77 \%$ & NS \\
\hline Ventilatory support (days) & $14.1(15.6)$ & $25.1(17.9)$ & $<0.005$ \\
\hline Respiratory support (days) & $38.7(23.4)$ & $57.9(28.1)$ & $<0.005$ \\
\hline Oxygen support (days) & 60.5 (53.4) & $89.5(38.8)$ & $<0.005$ \\
\hline CLD 28 days PNA & $79 \%$ & $94 \%$ & $<0.005$ \\
\hline CLD 36 weeks GA & $39 \%$ & $66 \%$ & $<0.005$ \\
\hline Systemic steroids & $56 \%$ & $80 \%$ & $<0.005$ \\
\hline Treated PDA & $55 \%$ & $46 \%$ & NS \\
\hline Inotropics & $65 \%$ & $71 \%$ & NS \\
\hline IVH > grade 1 & $33 \%$ & $43 \%$ & NS \\
\hline Leucomalacia & $9 \%$ & $8 \%$ & NS \\
\hline Renal insufficiency & $15 \%$ & $46 \%$ & $<0.005$ \\
\hline Phototherapy & $72 \%$ & $63 \%$ & NS \\
\hline Transfusions (number) & $6.4(4.8)$ & $10.8(5.3)$ & $<0.0005$ \\
\hline EPO & $20 \%$ & $9 \%$ & NS \\
\hline
\end{tabular}

threshold retinopathy. The association of lower Apgar score with an increased risk to develop ROP is described in literature. ${ }^{16}$ CRIB score was originally designed to quantify the relative risk of neonatal mortality but others linked CRIB score with morbidity characteristics during later neonatal stay. ${ }^{4}{ }^{17}$ Duration of parenteral nutrition in the EpiBel cohort is in line with the cohort described by Wallace et al and was a risk factor to develop threshold ROP. ${ }^{14}$ Respiratory markers remained strong risk factors to develop threshold retinopathy. Duration of respiratory support was the strongest risk factor in this cohort. Length of respiratory support or days on oxygen were somewhat shorter in our cohort, compared to the findings of De Jonge et al and were more in line with the cohort described by Hussain et al. ${ }^{89}$ There was no significant difference in prescription of inotropics in the EpiBel cohort. Overall prescription was high in our cohort $(66 \%)$ compared to the Mizoguchi cohort $(44 \%) .{ }^{18}$ The number of blood transfusions administered was significantly higher in threshold ROP cases. This association has repeatedly been described but Brooks et al could not document a protective effect of a restrictive transfusion policy on the development of threshold ROP. ${ }^{15}{ }^{19}$ The number of blood transfusions still remained a strong risk factor in the logistic regression analysis in this cohort.

Table 3 Relevant neonatal characteristics in infants who developed renal insufficiency $(>1.5 \mathrm{mg} / \mathrm{dll})$ compared to control infants in the EpiBel cohort

\begin{tabular}{llll}
\hline & Cases & Controls & p Value \\
\hline Number of infants & 37 & 138 & \\
GA (weeks) & $25.3(0.7)$ & $25.5(0.6)$ & $\mathrm{p}<0.05$ \\
Birth weight (g) & $784(174)$ & $815(154)$ & $\mathrm{p}<0.05$ \\
Apgar 5 minutes & $7.4(2.8)$ & $7.7(2.1)$ & $\mathrm{NS}$ \\
CRIB score & $5.9(3.3)$ & $5.3(3.2)$ & $\mathrm{p}<0.05$ \\
Parenteral nutrition (days) & $45.3(27.3)$ & $39.4(24.2)$ & $\mathrm{NS}$ \\
CLD 36 weeks GA & $54 \%$ & $42 \%$ & $\mathrm{NS}$ \\
Systemic steroids & $75 \%$ & $58 \%$ & $\mathrm{NS}$ \\
Treated PDA & $49 \%$ & $55 \%$ & $\mathrm{NS}$ \\
Transfusions (number) & $7.9(5.4)$ & $6.7(5.1)$ & $\mathrm{p}<0.05$ \\
Threshold ROP & $43 \%$ & $14 \%$ & $\mathrm{p}<0.005$ \\
\hline
\end{tabular}

$\mathrm{GA}=$ gestational age; $\mathrm{CRIB}=$ Clinical Risk Index for Babies; $\mathrm{CLD}=$ chronic lung disease; PDA = patent ductus arteriosus. 
Table 4 Results of the logistic regression analysis to evaluate the effect of different risk factors for threshold retinopathy in the EpiBel cohort (risk factors first documented by monovariate analysis)

\begin{tabular}{llll}
\hline & OR & $95 \% \mathrm{Cl}$ & $\mathrm{p}$ Value \\
\hline Transfusions (number) & 1.1189 & 1.0309 to 1.2145 & 0.0072 \\
Renal insufficiency & 3.3193 & 1.3442 to 8.1967 & 0.0093 \\
Respiratory support (days) & 1.0207 & 1.0021 to 1.0397 & 0.0291 \\
Birth weight & 0.9991 & 0.9954 to 1.0028 & $\mathrm{NS}$ \\
Gestational age (weeks) & 0.8378 & 0.4701 to 1.4932 & $\mathrm{NS}$ \\
CRIB score & 0.9913 & 0.8199 to 1.2145 & $\mathrm{NS}$ \\
\hline OR = odds ratio; Cl = confidence intervals; CRIB = Clinical Risk Index for Babies. & \\
\hline
\end{tabular}

Finally, we documented a strong association of renal insufficiency, either transitory or prolonged, with the development of threshold ROP. Even if we only considered prolonged renal insufficiency, this still remained a positive risk factor (cases 6/35 and controls 2/141, p<0.02). Renal insufficiency remained an independent risk factor in a multiple regression model even after correction for other variables (maternal hypertension, amnionitis, growth restriction, and PDA treatment) that might potentially explain a rise in creatinaemia. In addition, renal insufficiency was an independent risk factor in a logistic regression model. Defective microangiopathy and microperfusion might be the underlying common pathogenesis or creatinaemia might simply serve as an additional marker of severity of (cardiovascular) disease. This risk factor can be recognised earlier in life compared to respiratory characteristics and therefore, might be relevant in risk assessment. Unfortunately, this risk factor is more specific (119/ $138=86 \%)$ than sensitive $(16 / 37=43 \%)$. The reverse is more relevant in screening tools.

Although there are limitations in this study, based on the retrospective, multiple centre design and on the fact only data in inborn survivors were analysed, an overall high incidence of stage 3 and threshold retinopathy was documented in this cohort, in line with other cohorts in the literature. ${ }^{6-10}$ In addition, there is significant co-morbidity in the majority of infants who developed threshold ROP. Finally, besides risk factors already described, we documented renal insufficiency as an additional and not yet described risk factor to develop threshold ROP.

\section{ACKNOWLEDGEMENTS}

The EpiBel Study group comprises the neonatologists and gynaecologists in all 19 perinatal centres in Belgium who contributed data to the study whose invaluable help we acknowledge. Steering committee members included Bart Van Overmeire (Antwerp), Koenraad Smets (Ghent), Christian Debauche (Brussels), Jacques Lombet (Liège), Jean Bottu (Luxembourgh), Hugo Devlieger (Leuven), Piet Vanhaesebrouck (Ghent), Jacques Rigo (Liège), Karel Allegaert (Leuven), Anne François (Rocourt), Inge Vanherreweghe (Brussels), Martine Docx (Antwerp), Patrick Van Reempts (Antwerp).

\section{Authors' affiliations}

K Allegaert, H Devlieger, University Hospital, Gasthuisberg, Herestraat 49, 3000 Leuven, Belgium

K de Coen, University Hospital, De Pintelaan, 1859000 Ghent, Belgium This work was supported by the Belgian Ministry of Health.
These results were partially presented at the 18th European Congress of Perinatal Medicine, 19-22 June 2002 Oslo and at the annual Ross Conference, Hot Topics 2002 in Neonatology, 6-8 December, 2002 Washington DC.

\section{REFERENCES}

1 Termote J, Schalii-Delfos NE, Donders AR, et al. The incidence of visually impaired children with retinopathy of prematurity and their concomitant disabilities. J AAPOS 2003:7:131-6.

2 Vanhaesebrouck P, Allegaert K, Bottu J, et al. A population based study on outcome to discharge for extremely preterm infants born in Belgium during 1999-2000 (EpiBel study). 18th European Congress of Perinatal Medicine Oslo, 19-22 June 2002.

3 An International Classification Of Retinopathy Of Prematurity. Committee for the classification of Retinopathy of Prematurity. Arch Ophthalmol 1984;102:1130-4.

4 The International Neonatal Network. The CRIB (Clinical Risk Index for Babies) score: a tool for assessing initial neonatal risk and comparing performance of neonatal intensive care units. Lancet 1993;342:193-198.

5 Devlieger H, Martens G, Bekaert A, et al. Perinatal activities in Flanders 1996:94-116.

6 Costeloe K, Hennessy E, Gibson AT, et al. The EPICure study: outcomes to discharge from hospitals for infants born at threshold of viability. Pediatrics 2000; 106:659-71.

7 Larsson E, Carle-Petrelius B, Cernerud G, et al. Incidence of ROP in two consecutive Swedish population based studies. Br J Ophthalmol 2002;86:1122-6.

8 DeJonge MH, Khuntia A, Maisels MJ, et al. Bilirubin levels and severe retinopathy of prematurity in infants with estimated gestational ages of 23 to 26 weeks. J Pediatr 1999;135:102-4.

9 Hussain N, Clive J, Bhandari V. Current incidence of retinopathy of prematurity, 1989-1997. Pediatrics 1999;104:e26.

10 Bardin C, Zelkowitz P, Papageorgiou A. Outcome of small-for-gestational age and appropriate-for-gestational age infants born before 27 weeks of gestation. Pediatrics 1997;100:e4.

11 Holmstrom G, Thomassen P, Broberger U. Maternal risk factors for retinopathy of prematurity-a population-based study. Acta Obstet Gynecol Scand 1996:75:628-35.

12 Watts $\mathbf{P}$, Adams GG. In vitro fertilisation and stage 3 retinopathy of prematurity. Eye 2000;14:330-3.

13 Higgins RD, Mendelsohn AL, DeFeo MJ, et al. Antenatal dexamethasone and decreased severity of retinopathy of prematurity. Arch Ophthalmol 1998;116:601-5.

14 Wallace DK, Kylstra JA, Phillips SJ, et al. Poor postnatal weight gain: a risk factor for severe retinopathy of prematurity. J AAPOS 2000:4:343-7.

15 Allegaert K, Vanhole C, Casteels I, et al. Perinatal growth characteristics and associated risk to develop threshold retinopathy of prematurity. J AAPOS 2003;7:34-7.

16 The Italian ROP Study Group. Italian multicentre study on retinopathy of prematurity. Eur J Pediatr 1997;156:939-43.

17 Buhrer C, Grimmer I, Metze B, et al. The CRIB score and neurodevelopmental impairment at one year corrected age in very low birth weight infants. Intensive Care Med 2000;26:325-9.

18 Mizoguchi MB, Chu TG, Murphy FM, et al. Dopamin use is an indicator for the development of threshold retinopathy of prematurity. $\mathrm{Br} J$ Ophthalmol 1999;83:425-8.

19 Brooks SE, Marcus DM, Gillis D, et al. The effect of blood transfusion protocol on retinopathy of prematurity: a prospective, randomized study. Pediatrics 1999;104:514-518. 